\title{
Factors associated with depression among adolescents living with HIV in Malawi
}

\author{
Maria H. Kim ${ }^{1,2^{*}}$, Alick C. Mazenga ${ }^{2 \dagger}$, Xiaoying Yu ${ }^{3,4}$, Akash Devandra', Chi Nguyen ${ }^{3,4}$, Saeed Ahmed ${ }^{1}$,
} Peter N. Kazembe ${ }^{2}$ and Carla Sharp ${ }^{5}$

\begin{abstract}
Background: Prior research suggests that a high prevalence of depression, with a detrimental impact on treatment outcomes exists among HIV-infected youth. Data on potential risk factors of depression among HIV-infected youth in sub-Saharan Africa are scarce. This cross-sectional study aimed to identify contributory/protective factors associated with depression in Malawian adolescents 12-18 years old living with HIV.

Methods: Depression was measured by a validated Chichewa version of the Beck Depression Inventory version-॥ (BDI-II) and the Children's Depression Rating Scale-Revised (CDRS-R). Data on variables thought to potentially be contributory/protective were collected and included: socio-demographics, past traumatic events/stressors, behavioural factors/social support, and bio-clinical parameters. Chi-square test or two-sample t-test was used to explore associations between factors and depression. Additional testing via linear/logistic regression, adjusting for age and sex, identified candidate variables $(p<0.1)$. Final regression models included variables with significant main effects and interactions.
\end{abstract}

Results: Of the 562 participants enrolled (mean age, 14.5 years [SD 2.0]; $56.1 \%$ female), the prevalence of depression was $18.9 \%$. In multivariate linear regression, the variables significantly associated with higher BDI-II score were female gender, fewer years of schooling, death in the family/household, failing a school term/class, having a boyfriend/girlfriend, not disclosed or not having shared one's HIV status with someone else, more severe immunosuppression, and bullied for taking medications. Bullying victimization was reported by $11.6 \%$ of respondents. We found significant interactions: older participants with lower height-for-age z-scores and dissatisfied with their physical appearance had higher BDI-II scores. In multivariate logistic regression, factors significantly associated with depression were: older age, OR 1.23 (95 \% Cl 1.07-1.42); fewer years of schooling, OR 3.30 (95 \% Cl 1.54-7.05); and bullied for taking medications, (OR 4.20 (95 \% Cl 2.29-7.69).

Conclusion: Having fewer years of schooling and being bullied for taking medications were most clearly associated with depression. Programmes to support the mental health needs of HIV-infected adolescents that address issues such as disclosure, educational support, and, most notably, bullying may improve treatment outcomes and are recommended.

Keywords: Depression, Mental health, HIV AIDS, Adolescents, Africa, Bullying

\section{Background}

An estimated 2.1 million adolescents (aged 10-19 years) are living with HIV, the vast majority in sub-Saharan Africa [1]. Nearly half of new HIV infections occur in young people (aged 15-24 years) [1].

\footnotetext{
* Correspondence: mhkim@bcm.edu

${ }^{\dagger}$ Equal contributors

'Baylor College of Medicine International Paediatric AIDS Initiative, Texas

Children's Hospital, Houston, USA

${ }^{2}$ Baylor College of Medicine Children's Foundation Centre of Excellence

Malawi, Private Bag B-397, Lilongwe 3, Malawi, Africa

Full list of author information is available at the end of the article
}

As HIV services in sub-Saharan countries such as Malawi have successfully scaled up, improved survival rates of HIV-infected adolescents have raised awareness of the need for holistic care that takes into account mental health and quality-of-life issues. Adolescents living with HIV/AIDS are particularly vulnerable for a variety of biological, behavioural, social and structural reasons, and providing holistic care to this group presents many unique challenges $[1,2]$.

Globally, depression is a major contributor to the burden of disease worldwide and the number one cause of illness 
and disability amongst adolescents; with suicide ranking as the third most common cause of death [3]. The burden of disease is higher in low and middle-income countries [4]. Risk factors for depression in adolescents in the west include exposure to psychosocial stressors [4], bullying victimization [5-8], traumatic events, abuse [9, 10], and gender [4]. High-risk behaviours, such as earlier debut of sexual activity, substance misuse, and increased number of sexual partners, have also been associated with depression in youth $[8,11,12]$. In sub-Saharan Africa, evidence on factors potentially associated with depression amongst adolescents such as bullying [13], and substance abuse $[13,14]$ have just begun to emerge. Correlates, which might be particularly relevant in the African setting including orphanhood [15, 16], exposure to violence [17], poverty, and food insecurity, peer social support, and death in the family, and have been insufficiently described.

There is evidence of significant co-morbidity in patients with HIV/AIDS [18-20]. Among people living with HIV/ AIDS (PLWHA) in Africa, prevalence rates for depression range between $12 \%$ and $60 \%$ [11, 20-25]. Our recent study of depression in HIV-infected adolescents in Malawi revealed a prevalence rate of $18.9 \%$ [26]. Despite the increased interest in this field and the publication of several studies highlighting the high levels of depression in PLWHA, there continues to be a dearth of evidence related to adolescents and very little data examining the associated risk factors and correlates of depression in the HIVinfected adolescent population, especially in the African socio-cultural context. Studies in the West have pointed to a multifactorial aetiology of depression in HIV/AIDS that includes psychological, social, and biological factors. The few studies that have been conducted in sub-Saharan Africa suggest the following risk factors for depression in PLWHA: female gender, older age, unemployment, negative life events, childhood trauma, impaired function, poor social support, poor quality of life, and low CD4 counts [27-30]. There is a paucity of information regarding other potential correlates such as stigma, HIV associated bullying, HIV disclosure status, and self-image.

The relationship between depression and HIV appears to be bidirectional, with one exacerbating the other. Depression has been shown to worsen HIVrelated outcomes, including steeper declines in CD4 counts and more rapid progression to AIDS and death $[20,25,31,32]$. Associations also have been made with suboptimal adherence to antiretroviral therapy (ART) and treatment discontinuation, with serious implications for long-term treatment efficacy [33-35].

Malawi, a land-locked country in Southern Africa, has an adult HIV prevalence of $10.8 \%$ [36]. The national ART programme has been successfully scaled-up, and there were approximately 486,795 patients alive and on ART as of
March 2014 [37]. There is an expanding national Baylor Teen-Club programme focusing on holistic care for HIVinfected adolescents. However, awareness of mental health issues continues to be limited between both the public and healthcare providers, and few diagnostic and therapeutic options exist. Furthermore, there is little to no evidence regarding depression amongst HIV-infected adolescents in Malawi. Given the paucity of research we performed exploratory testing and included variables, based on prior research on adolescent depression, that were hypothesized to potentially contribute to or be protective of depression in HIV-infected adolescents in Malawi. We evaluated a wide range of factors: socio-demographic, past traumatic events/stressors (including bullying, self-image and school performance), behavioural factors/social support (including HIV disclosure), and bio-clinical parameters. The aim was to determine which factors remained associated once considered together, with the hope that enhanced understanding of these factors might contribute to the development of improved and comprehensive holistic adolescent ART services.

\section{Methods}

\section{Study design, population and setting}

We conducted a cross-sectional study to assess factors associated with depression among Malawian adolescents living with HIV. A convenience sample of $n=562$ youths aged 12-18 years were recruited over a period of 8 months in 2012. The study sites were the Baylor College of Medicine - Abbott Fund Children's Clinical Centre of Excellence (COE) and Zomba Central Hospital Tisungane ART Clinic. Zomba Tisungane ART Clinic is the main referral HIV clinic in southeastern Malawi, with more than 200 adolescents receiving care. Baylor COE, located in Lilongwe, the capital of Malawi, is the largest paediatric HIV clinic in Malawi, with more than 400 children receiving care. The COE serves as a national referral centre for paediatric and adolescent HIV care, and patients come from diverse regional and socioeconomic backgrounds.

\section{Study procedures}

Written informed assents and consents were obtained from the participants and caregivers, respectively. Upon assenting/consenting, participants completed the Chichewa version of the Beck Depression Inventory version II (BDI-II) [26], followed by a structured clinical interview using the Children's Depression Rating Scale Revised (CDRS-R). Interviewers were blinded to the results of the BDI-II. Finally, a socio-demographic behavioural questionnaire (SDBAQ) was administered. A mental health clinical officer trained clinician interviewers, with mental health training and over two years of experience in adolescent HIV care, in the administration of 
the CDRS-R [26]. Selected HIV-related clinical variables were extracted from patient electronic medical records and health passports. All participants with severe depression or suicidal ideation received counselling from onsite mental health professionals.

\section{Measures}

Depression was measured by a Chichewa version of the BDI-II [26] and the CDRS-R. Validation of these instruments is reported fully elsewhere [26]. In brief, the BDI-II is a self-rated depression screening instrument with 21 items and assesses the presence and severity of depressive symptoms in those $\geq 13$ years of age [38]. It has been validated in a range of settings [39-41]. The CDRS- $R$ is a clinician interview instrument used to both diagnose depression and to measure response to treatment in children $[26,42,43]$. It is one of the most widely used paediatric depression scales in international clinical research trials [26, 42, 44-46].

Data were collected (SDBAQ and medical record data extraction) on variables thought to be potentially associated with depression. Data included:

1. Socio-demographic factors: gender, age, education, family income level, location of their home, distance from clinic, primary caregiver type (father/mother, both parents, uncle/aunt, other/grandparent)

2. Past traumatic events/stressors: maternal death or employment status, change of caregiver, number of deaths in the family, failed school term, history of sexual or domestic violence, victim of teasing/ bullying for one's appearance or for taking medications, hospital admissions in the past year

3. Behavioural factors/social support: involvement in a romantic relationship, satisfaction with physical appearance, alcohol and drug use, tobacco use, HIV disclosure to another person, child's knowledge of HIV status and age at disclosure

4. Bio-clinical parameters: ART use, efavirenz-based regimen, second-line ART, history of $\mathrm{TB}$, initial and most recent $\mathrm{WHO}$ stage, initial and most recent CD4/immunological classification, prior diagnosis of depression, nutritional status, BMI-for-age z-score, height-for-age z-score.

\section{Statistical analysis for the depression manuscript}

Descriptive statistics, such as, mean, standard deviation (SD) for continuous variables, and frequency and proportion for categorical variables, were calculated among all subjects and by groups. For the BDI-II score, we performed explorative analysis using two-sample $t$-test, analysis of variance (ANOVA) or Pearson correlation. For CDRS-R score, we defined depression by having a score equal to or higher than 55 [26]. Chi-square test or two-sample $t$-test was used to explore the association between potential factors and depression. We collapsed categories for some variables with sparse cells or with similar outcome values. For example, we collapsed 'not in school' $(n=3)$ with 'Junior primary school', 'tertiary' $(\mathrm{n}=4)$ with 'junior/ senior secondary school' in meaningful way; we also combined the categories of 'mother alone' and 'father alone' for caregiver since the results demonstrated a similar degree of depression for two separate categories (19\% and $18 \%$ in depression by CDRS respectively). For correlated variables that measured similar features, we either combined the variables or selected the most important variable for further analysis. For example, we combined three variables related to violence (forced sex, physical abuse and witness physical violence in the home) into one variable with yes indicating experience on any of three; similarly we had two variables that referred to the caregiver, "who currently cares for this teenager' and 'who do you live with'. We chose to use the former since it is more relevant/meaningful to the provision of supportive HIV care. Malnutrition was categorized according to the National Center for Health Statistics reference standards. Z-scores for BMI and height-for-age were calculated using WHO growth standards

We assessed all variables thought to be potentially correlated with depression based on previously published research. The initial univariate analysis identified 28 variables thought to be possibly associated with depression ( $p$-value less than 0.25 or $p$-value less than 0.25 or associations postulated based on previously published research). We reassessed these variables by univariate linear/ logistic regression, and then we performed a second round of screening by adjusting for age and sex using linear/logistic regression (Tables 1 and 2). Eighteen candidates with $p$-values $<0.1$ from either model were entered into the multivariate regressions. For both the linear and logistic regressions, we included age and sex in the models, regardless of the statistical significance, and performed backwards selection on other variables with significance $\leq 0.05$. Two-way interactions were checked. Only biologically meaningful and significant interactions (such as age"satisfaction with appearance, and age*height) were retained. We rescaled age (age minus 12) so the main effect term of age could be meaningfully interpreted in the model that included interactions with age. Final models were checked by model diagnostic techniques such as residual analysis and influence statistics. Final models were checked by model diagnostic techniques such as residual analysis and influence statistics. For the logistic regression, overall fit was also assessed by Hosmer and Lemeshow Goodness-of-Fit. The beta coefficient from the linear regression, the odds ratio (OR) from logistic regression, and their $95 \%$ confidence interval $(\mathrm{CI})$ were reported to evaluate the association between the variable and outcome 
Table 1 Factors associated with BDI-II score (unadjusted and adjusted for sex and age)

\begin{tabular}{|c|c|c|c|c|c|}
\hline Variable & Mean (SD, N)/N (\%) & $\begin{array}{l}\text { Unadjusted Beta Coef } \\
(95 \% \mathrm{Cl})\end{array}$ & $\begin{array}{l}\text { Unadjusted } \\
p \text {-value }\end{array}$ & $\begin{array}{l}\text { Adjusted Beta Coef } \\
(95 \% \mathrm{Cl})\end{array}$ & $\begin{array}{l}\text { Adjusted } \\
p \text {-value }\end{array}$ \\
\hline \multicolumn{6}{|l|}{ Socio-demographic factors } \\
\hline \multicolumn{6}{|l|}{ School Grade } \\
\hline Not in school or Junior Primary School & $176(31.3)$ & $2.37[0.68-4.06]$ & 0.02 & $5.25[3.23-7.26]$ & $<0.0001$ \\
\hline Senior Primary School & $229(40.7)$ & $1.62[0.02-3.22]$ & & $3.5[1.78-5.22]$ & \\
\hline Secondary School or Tertiary & $157(27.9)$ & Reference & & Reference & \\
\hline \multicolumn{6}{|l|}{ Family's estimated combined income } \\
\hline Less than 14,000 MK per month & $171(31.8)$ & $0.36[-1.29-2.02]$ & 0.61 & $0.38[-1.26-2.02]$ & 0.64 \\
\hline $14,000-49,999$ MK per month & $117(21.8)$ & $-0.85[-2.69-0.99]$ & & $-0.79[-2.61-1.03]$ & \\
\hline More than 50,000 per month & $71(13.2)$ & $-0.48[-2.65-1.68]$ & & $-0.37[-2.52-1.77]$ & \\
\hline I do not know & $178(33.1)$ & Reference & & Reference & \\
\hline \multicolumn{6}{|l|}{ Location of home } \\
\hline In the city & $369(65.7)$ & $-1.24[-2.98-0.50]$ & 0.06 & $-1.49[-3.22-0.25]$ & 0.06 \\
\hline Just outside the city & $93(16.5)$ & $0.74[-1.48-2.97]$ & & $0.3[-1.92-2.52]$ & \\
\hline Rural area & $100(17.8)$ & Reference & & Reference & \\
\hline \multicolumn{6}{|l|}{ Time it takes to get to the clinic from home } \\
\hline 0-30minutes & $71(12.7)$ & $-0.88[-2.96-1.20]$ & 0.71 & $-0.92[-2.98-1.15]$ & 0.67 \\
\hline 31-60 minutes & $229(40.8)$ & $-0.15[-1.56-1.25]$ & & $-0.36[-1.76-1.04]$ & \\
\hline$>60$ minutes & $261(46.5)$ & Reference & & Reference & \\
\hline \multicolumn{6}{|l|}{ Primary caregiver type } \\
\hline Father/Mother & $178(31.7)$ & $-1.63[-3.39-0.13]$ & 0.01 & $-1.36[-3.12-0.39]$ & 0.02 \\
\hline Both parents & $112(19.9)$ & $-3.39[-5.36-1.42]$ & & $-3.09[-5.06-1.12]$ & \\
\hline Uncle/Aunt & $138(24.6)$ & $-1.5[-3.37-0.37]$ & & $-1.32[-3.18-0.54]$ & \\
\hline Other/Grandparent & $134(23.8)$ & Reference & & Reference & \\
\hline \multicolumn{6}{|l|}{ Past-traumatic events/stressors } \\
\hline \multicolumn{6}{|l|}{ Maternal death or employment status } \\
\hline Not working & $106(18.9)$ & $-0.95[-2.71-0.80]$ & 0.01 & $-0.8[-2.55-0.95]$ & 0.03 \\
\hline Self-employed & $103(18.3)$ & $-1.51[-3.29-0.26]$ & & $-1.37[-3.14-0.40]$ & \\
\hline Employed by someone else & $73(13)$ & $-3.22[-5.24-1.19]$ & & $-2.97[-4.99-0.95]$ & \\
\hline Died & $280(49.8)$ & Reference & & Reference & \\
\hline \multicolumn{6}{|l|}{ Change in caregiver } \\
\hline No change in caregiver & $422(75.2)$ & $-1.59[-3.10-0.08]$ & 0.04 & $-1.59[-3.09-0.09]$ & 0.04 \\
\hline Caregiver has changed once or more & $139(24.8)$ & Reference & & Reference & \\
\hline \multicolumn{6}{|l|}{ Experience of family/household deaths } \\
\hline Nobody in my family has died & $149(26.5)$ & $-2.42[-3.89-0.95]$ & 0.001 & $-2.51[-3.97-1.05]$ & 0.0008 \\
\hline One or more people have died & $413(73.5)$ & Reference & & Reference & \\
\hline \multicolumn{6}{|l|}{ Failed school term/class } \\
\hline No & $327(58.9)$ & $-1.64[-2.97-0.31]$ & 0.02 & $-1.73[-3.05-0.41]$ & 0.01 \\
\hline Yes & $228(41.1)$ & Reference & & Reference & \\
\hline \multicolumn{6}{|c|}{ Experience of forced sex, physical abuse, or witnessed physical violence in the home } \\
\hline No & $477(84.9)$ & $-3.16[-4.97-1.35]$ & 0.0006 & $-2.97[-4.79-1.15]$ & 0.001 \\
\hline Yes & $85(15.1)$ & Reference & & Reference & \\
\hline \multicolumn{6}{|c|}{ Experience of being bullied for one's physical appearance } \\
\hline No & $427(76.1)$ & $-3.11[-4.62-1.59]$ & 0.0001 & $-2.78[-4.31-1.25]$ & 0.0004 \\
\hline
\end{tabular}


Table 1 Factors associated with BDI-II score (unadjusted and adjusted for sex and age) (Continued)

\begin{tabular}{|c|c|c|c|c|c|}
\hline Yes & $134(23.9)$ & Reference & & Reference & \\
\hline \multicolumn{6}{|l|}{ Experience of being bullied for taking medicines } \\
\hline No & $459(88.4)$ & $-5.7[-7.75-3.64]$ & $<0.0001$ & $-5.3[-7.40-3.19]$ & $<0.0001$ \\
\hline Yes & $60(11.6)$ & Reference & & Reference & \\
\hline \multicolumn{6}{|l|}{ Hospital admissions in the past year } \\
\hline No & $510(90.7)$ & $-2.08[-4.34-0.17]$ & 0.07 & $-2.13[-4.36-0.10]$ & 0.06 \\
\hline Yes & $52(9.3)$ & Reference & & Reference & \\
\hline \multicolumn{6}{|l|}{ Behavioral factors/social support } \\
\hline \multicolumn{6}{|c|}{ Experience of being in a romantic relationship that did not involve sex } \\
\hline Never had a boyfriend/girlfriend & $479(85.4)$ & $-3.52[-5.35-1.69]$ & 0.0002 & $-2.96[-4.96-0.96]$ & 0.004 \\
\hline Yes, in the past or current & $82(14.6)$ & Reference & & Reference & \\
\hline \multicolumn{6}{|l|}{ Satisfaction with the way I look (physical appearance) } \\
\hline I am very happy with the way I look & $460(82)$ & $-4.65[-6.31-2.99]$ & $<0.0001$ & $-4.34[-6.00-2.68]$ & $<0.0001$ \\
\hline I am somewhat/ not at all satisfied with the way I look & $101(18)$ & Reference & & Reference & \\
\hline \multicolumn{6}{|l|}{ Use of alcohol in the past 30 days } \\
\hline Never & $547(97.3)$ & $-7.76[-11.77-3.74]$ & 0.0002 & $-7.35[-11.35-3.36]$ & 0.0003 \\
\hline Once a month or more & $15(2.7)$ & Reference & & Reference & \\
\hline \multicolumn{6}{|l|}{ HIV disclosure status* } \\
\hline Disclosed and have shared with someone & $273(48.6)$ & $0.19[-1.59-1.97]$ & 0.09 & $0.98[-2.86-0.97]$ & 0.02 \\
\hline Disclosed, have not shared with anyone & $184(32.7)$ & $1.68[-0.21-3.57]$ & & $0.98[-0.74-3.12]$ & \\
\hline Not disclosed & $105(18.7)$ & Reference & & Reference & \\
\hline Age at disclosure & $12.35(1.63,457)$ & $0.55[0.10-1.00]$ & 0.02 & $0.42[-0.09-0.92]$ & 0.11 \\
\hline \multicolumn{6}{|l|}{ Bio-clinical parameters } \\
\hline \multicolumn{6}{|l|}{ Child on ART } \\
\hline No & $36(6.4)$ & $0.83[-1.84-3.50]$ & 0.54 & $0.99[-1.66-3.64]$ & 0.46 \\
\hline Yes & $526(93.6)$ & Reference & & Reference & \\
\hline \multicolumn{6}{|l|}{ Efavirenz based ART regimen } \\
\hline No & $526(93.6)$ & $-0.71[-3.38-1.96]$ & 0.60 & $-0.71[-3.36-1.95]$ & 0.60 \\
\hline Yes & $36(6.4)$ & Reference & & Reference & \\
\hline \multicolumn{6}{|l|}{ Second line ART regimen } \\
\hline No & $491(87.4)$ & $0.68[-1.29-2.65]$ & 0.50 & $0.65[-1.33-2.63]$ & 0.52 \\
\hline Yes & $71(12.6)$ & Reference & & Reference & \\
\hline \multicolumn{6}{|l|}{ History of TB treatment } \\
\hline No & $309(55)$ & $0.77[-0.54-2.09]$ & 0.25 & $0.75[-0.55-2.06]$ & 0.26 \\
\hline Yes & $253(45)$ & Reference & & Reference & \\
\hline \multicolumn{6}{|l|}{ Initial WHO stage } \\
\hline WHO stage $1-2$ & $160(28.7)$ & $-0.12[-1.57-1.34]$ & 0.87 & $0.03[-1.42-1.47]$ & 0.97 \\
\hline WHO Stage 3-4 & $398(71.3)$ & Reference & & Reference & \\
\hline Most recent CD4 count & $516(307,509)$ & $0[-0.01-0.00]$ & 0.009 & $0[-0.00-0.00]$ & 0.02 \\
\hline \multicolumn{6}{|l|}{ HIV immunological classification (based on CD4) } \\
\hline None or not significant & $235(46.2)$ & $-2.34[-4.18-0.49]$ & 0.03 & $-2.26[-4.09-0.43]$ & 0.05 \\
\hline Mild & $112(22)$ & $-0.94[-3.05-1.18]$ & & $-1[-3.09-1.09]$ & \\
\hline Advanced & $68(13.4)$ & $-0.16[-2.56-2.25]$ & & $-0.15[-2.53-2.22]$ & \\
\hline Severe & $94(18.5)$ & Reference & & Reference & \\
\hline
\end{tabular}

Current nutritional status 
Table 1 Factors associated with BDI-II score (unadjusted and adjusted for sex and age) (Continued)

\begin{tabular}{|c|c|c|c|c|c|}
\hline Normal & $544(96.8)$ & $-2.44[-6.15-1.28]$ & 0.20 & $-3.14[-6.83-0.56]$ & 0.10 \\
\hline Malnourished & $18(3.2)$ & Reference & & Reference & \\
\hline BMl for age z-score & $-0.88(1.18,561)$ & $0.08[-0.48-0.63]$ & 0.79 & $-0.19[-0.76-0.39]$ & 0.52 \\
\hline Height for age z-score & $-1.79(1.16,561)$ & $-0.98[-1.54-0.42]$ & 0.0006 & $-1.31[-1.88-0.74]$ & $<0.0001$ \\
\hline
\end{tabular}

adjusting for other covariates. A $p$-value $<0.05$ was considered statistically significant, and SAS software version 9.3 (SAS Institute, Cary, N.C.) was used for all analyses.

\section{Ethics approvals}

Ethical approvals for this study were granted by the National Health Sciences Research Committee (Malawi) and the Baylor College of Medicine Institutional Review Board (USA).

\section{Results}

The clinics provided a list of 695 potential participants. Of these, 102 could not be contacted (death, loss-tofollow-up, insufficient contact information, and transferout to another facility); 11 could not participate due to intellectual disability. Of the remaining 582, 97 \% (562) consented/assented and enrolled in the study. The mean age of participants was 14.5 years (SD 2.0), and 315 (56.1\%) were female.

\section{Univariate analysis of associations between BDI-II score and other variables}

Mean BDI-II score for the total sample $(n=562)$ was 11.9 (SD 7.9) (Table 1, $p<0.1$ ). After adjustment for age and sex, a higher BDI-II score was potentially associated with fewer years of schooling, living in a rural area or outside the city, primary caregiver type (other/grandparent), maternal death, change in caregiver, death in the family/ household, failing a school term/class, experience of forced sex, physical abuse or witnessed physical violence in the home, bullied for one's physical appearance or for taking medicines, hospital admission in the past year, experience of being in a romantic relationship, dissatisfaction with physical appearance, use of alcohol, being disclosed to and not sharing one's HIV status with someone else, higher recent CD4 count/worse immunological stage, being malnourished, or lower height-for-age z-score. Bullying victimization for taking medications was reported by $11.6 \%$ of respondents.

\section{Univariate analysis of associations between depression and other variables}

The prevalence of depression as measured by the CDRS-R was $18.9 \%(106 / 562)$ (Table $2, p<0.1)$. After adjustment for age and sex, depression was potentially associated with fewer years of schooling, primary caregiver type (other/ grandparent), change in caregiver, experience of forced sex, physical abuse or witnessed physical violence in the home, bullied for one's physical appearance or for taking medicines, dissatisfaction with physical appearance, use of alcohol, older age at disclosure, worse immunological stage, and being malnourished.

\section{Multivariate analysis of associations between BDI-II score and other variables}

In multivariate analysis (Table 3 ), the variables significantly associated with higher BDI-II score were female gender, fewer years of schooling, death in the family/household, failing a school term/class, being teased for taking medications, being in a romantic relationship, not disclosed to or being disclosed to but not having shared one's HIV status with someone else, and worse level of immunosuppression. In addition, significant interactions were found between age and satisfaction with one's physical appearance and between age and height-for-age z-score (HAZ). Older age was associated with increased BDI-II score, and the effect of age on BDI-II depended on satisfaction with one's physical appearance and HAZ. Specifically, the negative values for the interaction terms imply that the more a patient was satisfied with his/her physical appearance or the higher the HAZ, the less was the effect of age on the BDI-II score. Thus, older participants with lower HAZ and who were dissatisfied with their physical appearance had higher BDI-II scores.

\section{Multivariate analysis of associations between depression and other variables}

In logistic regression (Table 4), fewer variables were significantly associated with depression: age, fewer years of schooling, and bullied for taking medications. Those who were bullied had increase odds (OR 4.20 [95 \% CI 2.29-7.69]) [25] of having depression.

\section{Discussion}

This is the first study to examine depression and associated factors among adolescents living with HIV in Malawi.

In multivariate linear regression, we found that a higher BDI-II score was associated with female gender, fewer years of schooling, death in the family/household, failing a school term/class, being bullied for taking medications, being in a romantic relationship, not being disclosed to or being disclosed to but not having shared one's HIV status with 
Table 2 Factors associated with depression (CDRS-R score >55) (unadjusted and adjusted for sex and age)

\begin{tabular}{|c|c|c|c|c|c|c|}
\hline Variable & $\begin{array}{l}\text { Mean }(S D, N) / \\
N(\%)\end{array}$ & $N(\%)$ & $\begin{array}{l}\text { Unadjusted OR } \\
(95 \% \mathrm{Cl})\end{array}$ & $\begin{array}{l}\text { Unadjusted } \\
p \text {-value } \\
\text { (overall) }\end{array}$ & $\begin{array}{l}\text { Adjusted OR } \\
(95 \% \mathrm{Cl})\end{array}$ & $\begin{array}{l}\text { Adjusted } \\
p \text {-value } \\
\text { (overall) }\end{array}$ \\
\hline \multicolumn{7}{|l|}{ Socio-demographic factors } \\
\hline \multicolumn{7}{|l|}{ School Grade } \\
\hline Not in school/Junior Primary School & $176(31.3)$ & $35(19.9)$ & $1.45[0.81-2.57]$ & 0.27 & $2.82[1.39-5.73]$ & 0.009 \\
\hline Senior Primary School & $229(40.7)$ & $48(21)$ & $1.54[0.90-2.66]$ & & $2.36[1.29-4.32]$ & \\
\hline Secondary School or Tertiary & $157(27.9)$ & $23(14.6)$ & Reference & & Reference & \\
\hline \multicolumn{7}{|l|}{ Family's estimated combined income } \\
\hline Less than 14,000 MK per month & $171(31.8)$ & $36(21.1)$ & $1.32[0.77-2.25]$ & 0.24 & $1.33[0.77-2.28]$ & 0.23 \\
\hline $14,000-49,999$ MK per month & $117(21.8)$ & $16(13.7)$ & $0.78[0.40-1.51]$ & & $0.79[0.41-1.54]$ & \\
\hline More than 50,000 per month & $71(13.2)$ & $17(23.9)$ & $1.55[0.79-3.04]$ & & $1.61[0.82-3.16]$ & \\
\hline I do not know & $178(33.1)$ & $30(16.9)$ & Reference & & Reference & \\
\hline \multicolumn{7}{|l|}{ Location of home } \\
\hline In the city & $369(65.7)$ & $67(18.2)$ & $0.83[0.48-1.45]$ & 0.81 & $0.78[0.45-1.36]$ & 0.69 \\
\hline Just outside the city & $93(16.5)$ & $18(19.4)$ & $0.9[0.45-1.83]$ & & $0.81[0.40-1.65]$ & \\
\hline Rural area & $100(17.8)$ & $21(21)$ & Reference & & Reference & \\
\hline \multicolumn{7}{|l|}{ Time it take to get to the clinic from home } \\
\hline 0-30minutes & $71(12.7)$ & $14(19.7)$ & $1.25[0.64-2.43]$ & 0.38 & $1.22[0.62-2.40]$ & 0.50 \\
\hline $31-60$ minutes & $229(40.8)$ & $49(21.4)$ & $1.38[0.88-2.17]$ & & $1.31[0.83-2.08]$ & \\
\hline$>60$ minutes & $261(46.5)$ & $43(16.5)$ & Reference & & Reference & \\
\hline \multicolumn{7}{|l|}{ Primary caregiver type } \\
\hline Father/Mother & $178(31.7)$ & $33(18.5)$ & $0.64[0.38-1.10]$ & 0.04 & $0.68[0.39-1.17]$ & 0.07 \\
\hline Both parents & $112(19.9)$ & $13(11.6)$ & $0.37[0.19-0.74]$ & & $0.4[0.20-0.81]$ & \\
\hline Uncle/Aunt & $138(24.6)$ & $25(18.1)$ & $0.63[0.35-1.12]$ & & $0.64[0.36-1.15]$ & \\
\hline Other/Grandparent & $134(23.8)$ & $35(26.1)$ & Reference & & Reference & \\
\hline \multicolumn{7}{|l|}{ Past-traumatic events/stressors } \\
\hline \multicolumn{7}{|l|}{ Maternal death or employment status } \\
\hline Not working & $106(18.9)$ & $19(17.9)$ & $0.77[0.43-1.36]$ & 0.21 & $0.8[0.45-1.43]$ & 0.31 \\
\hline Self-employed & $103(18.3)$ & $14(13.6)$ & $0.55[0.29-1.04]$ & & $0.58[0.30-1.09]$ & \\
\hline Employed by someone else & $73(13)$ & $11(15.1)$ & $0.62[0.31-1.26]$ & & $0.67[0.33-1.36]$ & \\
\hline Died & $280(49.8)$ & $62(22.1)$ & Reference & & Reference & \\
\hline \multicolumn{7}{|l|}{ Change in caregiver } \\
\hline No change in caregiver & $422(75.2)$ & $70(16.6)$ & $0.57[0.36-0.90]$ & 0.02 & $0.57[0.36-0.90]$ & 0.02 \\
\hline Caregiver has changed once or more & $139(24.8)$ & $36(25.9)$ & Reference & & Reference & \\
\hline \multicolumn{7}{|l|}{ Experience of family/household deaths } \\
\hline Nobody in my family has died & $149(26.5)$ & $22(14.8)$ & $0.68[0.41-1.13]$ & 0.14 & $0.67[0.40-1.12]$ & 0.12 \\
\hline One or more people have died & $413(73.5)$ & $84(20.3)$ & Reference & & Reference & \\
\hline \multicolumn{7}{|l|}{ Failed school term/class } \\
\hline No & $327(58.9)$ & $55(16.8)$ & $0.78[0.51-1.20]$ & 0.26 & $0.76[0.49-1.17]$ & 0.21 \\
\hline Yes & $228(41.1)$ & 47 (20.6) & Reference & & Reference & \\
\hline \multicolumn{7}{|c|}{ Experience of forced sex, physical abuse, or witnessed physical violence in the home } \\
\hline No & $477(84.9)$ & 79 (16.6) & $0.43[0.25-0.71]$ & 0.001 & $0.45[0.26-0.76]$ & 0.003 \\
\hline Yes & $85(15.1)$ & $27(31.8)$ & Reference & & Reference & \\
\hline \multicolumn{7}{|c|}{ Experience of being bullied for one's physical appearance } \\
\hline No & $427(76.1)$ & $70(16.4)$ & $0.53[0.34-0.85]$ & 0.008 & $0.58[0.36-0.93]$ & 0.02 \\
\hline
\end{tabular}


Table 2 Factors associated with depression (CDRS-R score >55) (unadjusted and adjusted for sex and age) (Continued)

\begin{tabular}{|c|c|c|c|c|c|c|}
\hline Yes & $134(23.9)$ & $36(26.9)$ & Reference & & Reference & \\
\hline \multicolumn{7}{|l|}{ Experience of being bullied for taking medicines } \\
\hline No & $459(88.4)$ & $73(15.9)$ & $0.23[0.13-0.41]$ & $<0.0001$ & $0.27[0.15-0.48]$ & $<0.0001$ \\
\hline Yes & $60(11.6)$ & $27(45)$ & Reference & & Reference & \\
\hline \multicolumn{7}{|l|}{ Hospital admissions in the past year } \\
\hline No & $510(90.7)$ & $92(18)$ & $0.6[0.31-1.15]$ & 0.12 & $0.58[0.30-1.13]$ & 0.11 \\
\hline Yes & $52(9.3)$ & $14(26.9)$ & Reference & & Reference & \\
\hline \multicolumn{7}{|l|}{ Behavioral factors/social support } \\
\hline \multicolumn{7}{|c|}{ Past history of being in a romantic relationship that did not involve sex } \\
\hline Never had a boyfriend/girlfriend & $479(85.4)$ & $83(17.3)$ & $0.54[0.31-0.92]$ & 0.02 & $0.65[0.36-1.18]$ & 0.16 \\
\hline Yes, in the past or current & $82(14.6)$ & $23(28)$ & Reference & & Reference & \\
\hline \multicolumn{7}{|l|}{ Satisfaction with the way I look (physical appearance) } \\
\hline I am very happy with the way I look & $460(82)$ & $77(16.7)$ & $0.5[0.30-0.82]$ & 0.006 & $0.54[0.33-0.89]$ & 0.02 \\
\hline I am somewhat/ not at all satisfied with the way I look & $101(18)$ & $29(28.7)$ & Reference & & Reference & \\
\hline \multicolumn{7}{|l|}{ Use of alcohol in the past 30 days } \\
\hline Never & $547(97.3)$ & $100(18.3)$ & $0.34[0.12-0.96]$ & 0.04 & $0.37[0.13-1.07]$ & 0.07 \\
\hline Once a month or more & $15(2.7)$ & $6(40)$ & Reference & & Reference & \\
\hline \multicolumn{7}{|l|}{ HIV disclosure status* } \\
\hline Disclosed and have shared with someone & $273(48.6)$ & $51(18.7)$ & $1.19[0.65-2.17]$ & 0.64 & $0.90[0.47-1.75]$ & 0.54 \\
\hline Disclosed, have not shared with anyone & $184(32.7)$ & $38(20.7)$ & $1.35[0.72-2.53]$ & & $1.19[0.62-2.28]$ & \\
\hline Not disclosed & $105(18.7)$ & $17(16.2)$ & Reference & & Reference & \\
\hline Age at disclosure & $12.3(1.6,4.6)$ & & $1.27[1.11-1.47]$ & 0.0008 & $1.31[1.11-1.56]$ & 0.002 \\
\hline \multicolumn{7}{|l|}{ Bio-clinical parameters } \\
\hline \multicolumn{7}{|l|}{ Child on ART } \\
\hline No & $36(6.4)$ & $4(11.1)$ & $0.52[0.18-1.50]$ & 0.23 & $0.54[0.18-1.56]$ & 0.25 \\
\hline Yes & $526(93.6)$ & $102(19.4)$ & Reference & & Reference & \\
\hline \multicolumn{7}{|l|}{ Efavirenz based ART regimen } \\
\hline No & $526(93.6)$ & $103(19.6)$ & $2.68[0.81-8.90]$ & 0.11 & $2.75[0.82-9.19]$ & 0.10 \\
\hline Yes & $36(6.4)$ & $3(8.3)$ & Reference & & Reference & \\
\hline \multicolumn{7}{|l|}{ Second line ART regimen } \\
\hline No & $491(87.4)$ & $94(19.1)$ & $1.16[0.60-2.25]$ & 0.65 & $1.18[0.60-2.31]$ & 0.63 \\
\hline Yes & $71(12.6)$ & $12(16.9)$ & Reference & & Reference & \\
\hline \multicolumn{7}{|l|}{ History of TB treatment } \\
\hline No & $309(55)$ & $61(19.7)$ & $1.14[0.74-1.74]$ & 0.56 & $1.13[0.74-1.75]$ & 0.56 \\
\hline Yes & $253(45)$ & $45(17.8)$ & Reference & & Reference & \\
\hline \multicolumn{7}{|l|}{ Initial WHO stage } \\
\hline WHO stage 1-2 & $160(28.7)$ & $28(17.5)$ & $0.88[0.55-1.43]$ & 0.61 & $0.91[0.56-1.47]$ & 0.71 \\
\hline WHO Stage 3-4 & $398(71.3)$ & $77(19.3)$ & Reference & & Reference & \\
\hline Most recent CD4 count & $516(307,509)$ & & 1 [1.00-1.00] & 0.08 & $1[1.00-1.00]$ & 0.12 \\
\hline \multicolumn{7}{|l|}{ HIV immunological classification } \\
\hline None or not significant & $235(46.2)$ & $32(13.6)$ & $0.58[0.31-1.08]$ & 0.04 & $0.6[0.32-1.13]$ & 0.05 \\
\hline Mild & $112(22)$ & $15(13.4)$ & $0.57[0.27-1.19]$ & & $0.57[0.27-1.19]$ & \\
\hline Advanced & $68(13.4)$ & $18(26.5)$ & $1.33[0.64-2.77]$ & & $1.35[0.64-2.82]$ & \\
\hline Severe & $94(18.5)$ & $20(21.3)$ & Reference & & Reference & \\
\hline
\end{tabular}

Current nutritional status 
Table 2 Factors associated with depression (CDRS-R score >55) (unadjusted and adjusted for sex and age) (Continued)

\begin{tabular}{lllllll}
\hline Normal & $544(96.8)$ & $100(18.4)$ & $0.45[0.17-1.23]$ & 0.12 & $0.38[0.13-1.05]$ & 0.06 \\
Malnourished & $18(3.2)$ & $6(33.3)$ & Reference & & Reference \\
BMl for age z-score & $-0.88(1.18,561)$ & & $0.96[0.80-1.14]$ & 0.61 & $0.89[0.74-1.08]$ & 0.24 \\
Height for age z-score & $-1.79(1.16,561)$ & & $0.93[0.78-1.12]$ & 0.46 & $0.87[0.72-1.06]$ & 0.17 \\
\hline
\end{tabular}

someone else, and immunosuppression. Older participants with lower HAZ and dissatisfaction with their physical appearance had higher BDI-II scores.

Multivariate logistic regression with depression as the dependent variable identified much fewer associations, with only three variables significantly associated with depression in both the linear and logistic models: older age, fewer years of schooling, and bullied for taking medications. The identification of fewer associations in logistic regression is partially explained by inadequate power related to analysing categorical vs. continuous outcomes. In addition, the results may reflect differences in the construct being measured (continuous vs. categorical) or the scales themselves.

There is a paucity of studies examining factors associated with adolescent depression in sub-Saharan Africa. However, the relationship between increasing age in adolescence and depression has been documented in studies from the developed world [47], and an association with suicidality has been noted in a study of HIV-infected adolescents in Kenya [25]. Our study identified an association between schooling and depression: specifically, fewer years of schooling (in both linear/logistic regression models) and failing a school term (linear regression) increased the likelihood of depression. The aforementioned study from Kenya [25] also identified a relationship between not being in an age-appropriate class and having a psychiatric disorder. Although intelligence and cognitive deficits related to HIV infection were not assessed in the present study, other studies have found higher cognitive deficits [48-50] and overall lower IQ scores in HIV-infected children [51]. Additional associations found to be related to depression in prior studies that were also found to be related in the linear regression include female gender [39], the presence of immunosuppression [52], disclosure $[53,54]$, and death in the family.

As compared to prior studies in the west or subSaharan Africa amongst non-HIV infected adolescents, several HIV-related potential risk factors for depression were highlighted in the present study. Specifically, stunting, immunosuppression, dissatisfaction with one's physical appearance, and fewer years of or failing school - all possibly the result of HIV infection, were found to be significantly associated with depression. Earlier identification of HIV infection in children with prompt initiation of ART could improve growth potential, immunity, physical appearance, and intellectual capacity and could therefore prevent many of these potential risk factors for depression amongst HIVinfected adolescents.

To our knowledge, our study is among the first to demonstrate a strong independent association between bullying and depression in sub-Saharan Africa; and the first to examine bullying related to HIV. Bullying is associated with severe mental health symptoms, including self-harm, and contributes independently to mental health problems [55]. In our study, $11.6 \%$ of respondents reported being bullied for taking medications, and bullying victimization arose as the variable most significantly associated with depression in both the linear (beta coefficient 5.31 [95\% CI 3.19, 7.43]) and logistic (OR 4.20 [95 \% CI 2.29]) regressions. Bullying has been established as an independent risk factor for depression in high-income countries and more recently is emerging as a risk factor in resourcelimited settings $[13,56]$. A recent study from India reported that children orphaned by AIDS were significantly more likely to report being bullied by friends or relatives than those orphaned due to other reasons [56]. As our study was cross-sectional, we cannot comment on whether or not children with depression are more likely to report bullying or if bullying leads to depression. Furthermore, our study did not directly measure potential HIV/AIDSrelated stigma, although presumably bullying for taking medications is likely associated with stigma. However, a longitudinal study from South Africa reported that significant indirect effects via bullying victimization were obtained for both anxiety and depression scores. These effects were independent of poverty, HIV/ AIDS-related stigma, and baseline mental health. The authors concluded that their data highlight bullying victimization as a potential target for future intervention efforts [57].

Due to the cross-sectional nature of this study, we cannot conclude any causal relationships. However, based on our data, we would also [57] recommend that bullying prevention programs may improve mental health outcomes for Malawian adolescents living with HIV and should be a focus of future research and programming. Some preliminary suggestions for interventions include teacher or school-based trainings to address bullying in HIV- and adolescent-support groups such as teen clubs, which may include curricula that directly address bullying. In our study, adolescents who were not in school or had completed only junior primary school had increased odds 
Table 3 Final Multivariate Linear Regression Model of factors associated with depression as measured by BDI-II

\begin{tabular}{|c|c|c|}
\hline Variable & Beta Coefficient [95\% Cl] & $P$-value \\
\hline Age & $0.54[-0.38,1.46]$ & 0.25 \\
\hline Female & $2.13[0.82,3.43]$ & 0.002 \\
\hline \multicolumn{3}{|l|}{ Grade } \\
\hline Not in school/Junior Primary School & $3.84[1.71,5.98]$ & \multirow[t]{3}{*}{0.0005} \\
\hline Senior Primary School & $3.17[1.45,4.89]$ & \\
\hline Secondary School or Tertiary & Reference & \\
\hline Nobody in my family has died & $-1.77[-3.15,-0.39]$ & 0.01 \\
\hline Did not fail school term/class & $-1.46[-2.76,-0.17]$ & 0.03 \\
\hline Bullying for taking medication & $5.31[3.19,7.43]$ & $<0.0001$ \\
\hline Never had a boyfriend/girlfriend & $-2.38[-4.35,-0.41]$ & 0.02 \\
\hline Satisfaction with physical appearance- happy with the way I look & $-1.06[-3.74,1.63]$ & 0.44 \\
\hline \multicolumn{3}{|l|}{ HIV disclosure status } \\
\hline Disclosed and have shared with someone & $-1.83[-3.79,0.13]$ & \multirow[t]{4}{*}{0.02} \\
\hline Disclosed, have not shared with anyone & $0.23[-1.65,2.10]$ & \\
\hline Not disclosed & Reference & \\
\hline \multicolumn{2}{|l|}{ Level of immunosuppression } & \\
\hline None or not significant & $-2.58[-4.29,-0.87]$ & \multirow[t]{4}{*}{0.0009} \\
\hline Mild & $-0.10[-2.08,1.88]$ & \\
\hline Advanced & $0.23[-2.00,2.47]$ & \\
\hline Severe & Reference & \\
\hline Height for age z-score & $0.23[-0.67,1.12]$ & 0.62 \\
\hline Age $^{*}$ satisfaction with physical appearance interaction & $-0.93[-1.74,-0.11]$ & 0.03 \\
\hline Age* Height for age $z$-score interaction & $-0.39[-0.68,-0.11]$ & 0.007 \\
\hline
\end{tabular}

of depression as compared to adolescents with more education (OR 3.30 [1.54, 7.05]; $p=0.0051$ ). Interventions that support children to remain in school may help to prevent depression. Stunting (low HAZ) and immunosuppression also were both independently associated with higher mean BDI-II scores. Interventions to facilitate prompt diagnosis of HIV and initiation of ART would prevent the on-towards effects of stunting and improve immunosuppression among HIV-infected adolescents.

The strengths of the study include the relatively large, geographically diverse sample and the measurement of an

Table 4 Final Multivariate Logistic Regression Model of factors associated with depression as measured by CDRS-R*

\begin{tabular}{lll}
\hline Variable & OR [95 \% Cl] & $P$-value \\
\hline Age & $1.23[1.07,1.42]$ & 0.004 \\
Female & $1.43[0.89,2.29]$ & 0.14 \\
Grade & & \\
Not in school/ Junior Primary School & $3.30[1.54,7.05]$ & 0.005 \\
Senior Primary School & $2.62[1.37,5.03]$ & \\
Secondary School or Tertiary & Reference & \\
Bullied for taking medication & $4.20[2.29,7.69]$ & $<0.0001$ \\
\hline
\end{tabular}

${ }^{*}$ As measured by CDRS-R extensive range of variables previously shown or thought to be associated with depression among HIV-infected youth. In addition, we used both a validated depressionscreening instrument (translated BDI-II) as a continuous outcome and a structured diagnostic interview (CDRS-R) as a categorical outcome. Finally, to our knowledge, this is the first study to examined factors associated with depression amongst HIV-infected adolescents in Malawi.

There were several limitations. As aforementioned, the design of the study was cross-sectional; therefore, we are unable to conclude any causal direction of the associations found and have no information regarding timing/onset of depression. Also although data collectors were trained on how to administer the SDBAQ, we did not perform inter-rater reliability testing. We also did not assess potential co-morbidities such as anxiety or intellectual disability. Due to depressive cognitive bias, youth with depression may have been more likely to report bullying/teasing. Finally, many of the variables were self-reported and, therefore, may be influenced by social desirability bias. Future studies could include longitudinal evaluations to measure temporal associations and should examine the relationship between depression and adherence in this group. 


\section{Conclusion}

In conclusion, we found that fewer years of schooling and bullying for taking medications were most clearly associated with depression, with the latter being the strongest independent determinant of depression. Programmes that help to identify and address the mental health needs of HIV-infected adolescents will contribute to solidifying global progress in expanding paediatric HIV treatment services.

\section{Abbreviations}

ART: (Antiretroviral therapy); BDI-II: (Beck depression inventory version-II); CDRS-R: (Children's depression rating scale-revised); HAZ: (Height-for-age zscore); PLWHA: (People living with HIV and AIDS); SDBAQ: (Sociodemographic behavioural questionnaire).

\section{Competing interests}

The authors have no competing interests to declare.

\section{Authors' contributions}

MHK and ACM conceived and designed the study, were responsible for study coordination and data management, helped analyze the data, interpret findings and wrote the manuscript. AD assisted in reviewing the protocol and study coordination in the field, contributed to data management and reviewed the manuscript for important intellectual content. PNK and SA reviewed the study protocol, provided guidance on the conduct of the study and critically reviewed the manuscript for important intellectual content. CN, XY and CS assisted in statistical analysis, interpretation and manuscript writing. All authors have read and approved the final manuscript.

\section{Acknowledgment}

We thank the Malawi Ministry of Health and Dignitas International for their partnership in this endeavor. We thank the Baylor College of Medicine Children's Foundation Malawi data team, clinicians and nurses who participated in data collection including Menard Bvumbwe, William Kamiyango, Mphatso Machika, and Adamson Munthali. Special thanks to Joseph Mhango for creation of the study database. We thank Dr. B. Lee Ligon, Center for Research, Innovation and Scholarship (CRIS), Department of Pediatrics, Baylor College of Medicine, for editorial assistance. We are grateful to all the adolescents living with HIV who participated in this study. This study was made possible by support from the Texas Children's Global Health Stimulus Grant and USAID cooperative agreement number 674-A-00-10-00093-00. MHK was supported by the Fogarty International Center of the National Institutes of Health under award number K01 TW009644. Data analysis was provided by the Design and Analysis Core of the Baylor-UT Houston Center for AIDS Research, an NIH funded program numbered P30-Al36211.

\section{Disclaimer}

The contents are the responsibility of the authors and do not necessarily reflect the views of the funders, including the National Institutes of Health, USAID and the United States Government.

\section{Author details}

${ }^{1}$ Baylor College of Medicine International Paediatric AIDS Initiative, Texas Children's Hospital, Houston, USA. Baylor College of Medicine Children's Foundation Centre of Excellence Malawi, Private Bag B-397, Lilongwe 3, Malawi, Africa. ${ }^{3}$ Department of Medicine Baylor College of Medicine, Houston, TX, USA. ${ }^{4}$ Design and Analysis Core, Baylor-UT Houston Center for AIDS Research, Houston, TX, USA. ${ }^{5}$ Department of Psychology, University of Houston, Houston, TX, USA.

\section{Received: 27 March 2015 Accepted: 14 October 2015}

Published online: 26 October 2015

\section{References}

1. UNICEF. Opportunity in Crisis Preventing HIV from Early Adolescence to young adulthood. In New York: UNICEF; 2011.

2. UNAIDS. Securing the Future Today Synthesis of Strategic Information on HIV and Young People. In Geneva: UNAIDS; 2011.
3. Dick B, Ferguson BJ. Health for the world's adolescents: a second chance in the second decade. J adolesc health : official publication of the Society for Adolescent Medicine. 2015;56(1):3-6.

4. Thapar A, Collishaw S, Pine DS, Thapar AK. Depression in adolescence. Lancet. 2012;379(9820):1056-67.

5. Prinstein MJ, Boergers J, Vernberg EM. Overt and relational aggression in adolescents: Social-psychological adjustment of aggressors and victims. J Clin Child Psychol. 2001;30(4):479-91.

6. Casement MD, Guyer AE, Hipwell AE, McAloon RL, Hoffmann AM, Keenan $K E$, et al. Girls' challenging social experiences in early adolescence predict neural response to rewards and depressive symptoms. Dev Cogn Neurosci. 2014;8:18-27.

7. Hawker DS, Boulton MJ. Twenty years' research on peer victimization and psychosocial maladjustment: a meta-analytic review of cross-sectional studies. J Child Psychol Psychiatry. 2000;41(4):441-55.

8. Saluja G, lachan R, Scheidt PC, Overpeck MD, Sun W, Giedd JN. Prevalence of and risk factors for depressive symptoms among young adolescents. Arch Pediatr Adolesc Med. 2004;158(8):760-5.

9. Ward CL, Flisher AJ, Zissis C, Muller M, Lombard C. Exposure to violence and its relationship to psychopathology in adolescents. Inj Prev. 2001;7(4):297-301.

10. Kim J, Cicchetti D. Longitudinal trajectories of self-system processes and depressive symptoms among maltreated and nonmaltreated children. Child Dev. 2006;77(3):624-39.

11. Nduna M, Jewkes RK, Dunkle KL, Shai NP, Colman I. Associations between depressive symptoms, sexual behaviour and relationship characteristics: a prospective cohort study of young women and men in the Eastern Cape. J Int AIDS Soc. 2010;13:44.

12. Rubin AG, Gold MA, Primack BA. Associations between depressive symptoms and sexual risk behavior in a diverse sample of female adolescents. J Pediatr Adolesc Gynecol. 2009;22(5):306-12.

13. Rudatsikira E, Muula AS, Siziya S, Twa-Twa J. Suicidal ideation and associated factors among school-going adolescents in rural Uganda. BMC Psychiatry. 2007;7:67.

14. Muula AS, Kazembe LN, Rudatsikira E, Siziya S. Suicidal ideation and associated factors among in-school adolescents in Zambia. Tanzan Health Res Bull. 2007;9(3):202-6.

15. Cluver L, Gardner F, Operario D. Psychological distress amongst AIDS-orphaned children in urban South Africa. J Child Psychol Psychiatry. 2007:48(8):755-63.

16. Ruiz-Casares M, Thombs BD, Rousseau C. The association of single and double orphanhood with symptoms of depression among children and adolescents in Namibia. Eur Child Adolesc Psychiatry. 2009;18(6):369-76.

17. Suliman S, Mkabile SG, Fincham DS, Ahmed R, Stein DJ, Seedat S. Cumulative effect of multiple trauma on symptoms of posttraumatic stress disorder, anxiety, and depression in adolescents. Compr Psychiatry. 2009;50(2):121-7

18. WHO. The World Health Report 2001: Mental Health: new understanding, new hope. In. Geneva: World Health Organization; 2001.

19. WHO. Global Burden of Disease, 2004 Update. In. Geneva: World Health Organization; 2008.

20. World Federation for Mental Health. An International Mental Health Awareness Packet from the WFMH Africa Initiative on Mental Health and HIV/AIDS. In: HIV/AIDS and Depression in Africa. Woodbridge, VA; 2009: 46.

21. Gupta RD, Packel M, Rutherford L, Leiter G, Phaladze K, Korte N, et al. Depression and HIV in Botswana: a population-based study on gender-specific socioeconomic and behavioral correlates. PLoS One. 2010;5(12), e14252.

22. Nakasujja N, Skolasky RL, Musisi S, Allebeck P, Robertson K, Ronald A, et al. Depression symptoms and cognitive function among individuals with advanced HIV infection initiating HAART in Uganda. BMC Psychiatry. 2010;10:44.

23. Mwale C, Stewart R, Mathanga D. The prevalence of psychological distress and associated factors among people living with Aids attending antiretroviral therapy clinics in Mzuzu, Malawi: A cross sectional descriptive study. Typescript. Blantyre: University of Malawi College of Medicine; 2006.

24. Traube D, Dukay V, Kaaya S, Reyes H, Mellins C. Cross-cultural adaptation of the Child Depression Inventory for use in Tanzania with children affected by HIV. Vulnerable Child Youth Student Studies. 2010;5(2):174-87.

25. Kamau JW, Kuria W, Mathai M, Atwoli L, Kangethe R. Psychiatric morbidity among HIV-infected children and adolescents in a resource-poor Kenyan urban community. AIDS Care. 2012;24(7):836-42.

26. Kim MH, Mazenga AC, Devandra A, Ahmed S, Kazembe PN, Yu X, et al. Prevalence of depression and validation of the Beck Depression Inventory-II 
and the Children's Depression Inventory-Short amongst HIV-positive adolescents in Malawi. J Int AIDS Soc. 2014;17:18965.

27. Myer L, Smit J, Roux LL, Parker S, Stein DJ, Seedat S. Common mental disorders among HIV-infected individuals in South Africa: prevalence, predictors, and validation of brief psychiatric rating scales. AIDS Patient Care STDS. 2008:22(2):147-58.

28. Kaharuza FM, Bunnell R, Moss S, Purcell DW, Bikaako-Kajura W, Wamai N, et al. Depression and CD4 cell count among persons with HIV infection in Uganda. AIDS Behav. 2006;10(4 Suppl):S105-11.

29. Kinyanda E, Hoskins S, Nakku J, Nawaz S, Patel V. Prevalence and risk factors of major depressive disorder in HIV/AIDS as seen in semi-urban Entebbe district, Uganda. BMC Psychiatry. 2011;11(205):11-205.

30. Klis S, Velding K, Gidron Y, Peterson K. Posttraumatic stress and depressive symptoms among people living with HIV in the Gambia. AIDS Care. 2011;23(4):426-34

31. Farinpour R, Miller EN, Satz P, Selnes OA, Cohen BA, Becker JT. Psychosocia risk factors of HIV morbidity and mortality: findings from the Multicenter AIDS Cohort Study (MACS). J Clin Exp Neuropsychol. 2003;25(5):654-70.

32. Cruess DG, Petitto JM, Leserman J, Douglas SD, Gettes DR, Ten Have TR, Depression and HIV infection: impact on immune function and disease progression. CNS Spectr. 2003;8(1):52-8.

33. Treisman GJ, Angelino AF, Hutton HE. Psychiatric issues in the management of patients with HIV infection. JAMA. 2001;286(22):2857-64

34. Holzemer WLC, Nokes IB, Turner KM, Brown JG, Powell-Cope MA, Inouye GM, et al. Predictors of self-reported adherence in persons living with HIV disease. AIDS Patient Care STDS. 1999;13(3):185-97.

35. Gonzalez JS, Batchelder AW, Psaros C, Safren SA. Depression and HIV/AIDS treatment nonadherence: a review and meta-analysis. J Acquir Immune Defic Syndr. 2011;58(2):181-7.

36. Malawi: HIV and AIDS estimates (2013) [http://www.unaids.org/en/ regionscountries/countries/malawi]

37. Malawi Ministry of Health. Government of Malawi Ministry of Health Integrated HIV Program Report January -March 2014. In Lilongwe: Ministry of Health; 2014: 60.

38. Beck A, Steer RA, Brown, GK: RCMAR Measurement Tools: Beck Depression Inventory - 2nd Edition (BDI-II). 2006. Available from: http:// academicdepartments.musc.edu/family_medicine/rcmar/beck.htm.

39. Adewuya AO, Ola BA, Aloba OO. Prevalence of major depressive disorders and a validation of the Beck Depression Inventory among Nigerian adolescents. Eur Child Adolesc Psychiatry. 2007;16(5):287-92.

40. Basker MM, Russell PS, Russell S, Moses PD. Validation of the children's depression rating scale- revised for adolescents in primary-care pediatric use in India. Indian J Med Sci. 2010;64(2):72-80.

41. Rivera CL, Bernal G, Rossello J. The Chidlren Depression Inventory (CDI) and the Beck Depression Inventory (BDI): Their Validity as Acreening Measures for Major Depression in a group of Puerto Rican Adolescents. International Journal of Clinical and Helath Psychology. 2005;5(3):485-98.

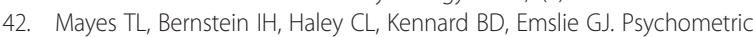
properties of the Children's Depression Rating Scale-Revised in adolescents. J Child Adolesc Psychopharmacol. 2010;20(6):513-6.

43. Children's Depression Inventory - Second Edition (CDI-2) [Internet] Toronto. Multi Health Systems Inc. 2004. Available from: http:// www.mhs.com/product.aspx?gr=edu\&prod=cdi2\&id=overview\#scales.

44. Plener PL, Grieb J, Sprober N, Straub J, Schneider A, Keller F, et al. Convergence of children's depression rating scale-revised scores and clinical diagnosis in rating adolescent depressive symptomatology. Ment IIIn. 2012;4(1):29-31.

45. Zalsman G, Misgav S, Sommerfeld E, Kohn Y, Brunstein-Klomek A, Diller R, et al. Children's Depression Inventory (CDI) and the Children's Depression Rating Scale-Revised (CDRS-R): Reliability of the Hebrew version. Int J Adolesc Med Health. 2011;17(3):255-7.

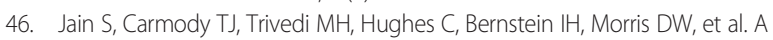
psychometric evaluation of the CDRS and MADRS in assessing depressive symptoms in children. J Am Acad Child Adolesc Psychiatry. 2007;46(9):1204-12.

47. Mellins CA, Malee KM. Understanding the mental health of youth living with perinatal HIV infection: lessons learned and current challenges. J Int AIDS Soc. 2013;16:18593.

48. Wood SM, Shah SS, Steenhoff AP, Rutstein RM. The impact of AIDS diagnoses on long-term neurocognitive and psychiatric outcomes of surviving adolescents with perinatally acquired HIV. AIDS (London, England). 2009:23(14):1859-65.
49. Boivin MJ, Green SD, Davies AG, Giordani B, Mokili JK, Cutting WA. A preliminary evaluation of the cognitive and motor effects of pediatric HIV infection in Zairian children. Health psychol : official journal of the Division of Health Psychology, American Psychological Association. 1995;14(1):13-21.

50. Drotar D, Olness K, Wiznitzer M, Schatschneider C, Marum L, Guay L, et al. Neurodevelopmental outcomes of Ugandan infants with HIV infection: an application of growth curve analysis. Health psychol : official journal of the Division of Health Psychology, American Psychological Association. 1999;18(2):114-21.

51. Nozyce ML, Lee SS, Wiznia A, Nachman S, Mofenson LM, Smith ME, et al. A behavioral and cognitive profile of clinically stable HIV-infected children. Pediatrics. 2006;117(3):763-70.

52. Misdrahi D, Vila G, Funk-Brentano I, Tardieu M, Blanche S, Mouren-Simeoni MC. DSM-IV mental disorders and neurological complications in children and adolescents with human immunodeficiency virus type 1 infection (HIV-1). Eur psychiatry : the journal of the Association of European Psychiatrists. 2004;19(3):182-4

53. Elliott-DeSorbo DK, Martin S, Wolters PL. Stressful life events and their relationship to psychological and medical functioning in children and adolescents with HIV infection. J Acquir Immune Defic Syndr. 2009:52(3):364-70.

54. Wiener LS, Battles HB. Untangling the web: A close look at diagnosis disclosure among HIV-infected adolescents. J Adolesc Health. 2006;38(3):307-9.

55. Arseneault $L$, Bowes $L$, Shakoor $S$. Bullying victimization in youths and mental health problems: 'much ado about nothing'? Psychol Med. 2010;40(5):717-29.

56. Kumar SP, Dandona R, Kumar GA, Ramgopal S, Dandona L. Depression among AIDS-orphaned children higher than among other orphaned children in southern India. Int j ment heal systs. 2014;8:13.

57. Boyes ME, Cluver LD. Relationships Between Familial HIV/AIDS and Symptoms of Anxiety and Depression: The Mediating Effect of Bullying Victimization in a Prospective Sample of South African Children and Adolescents. J Youth Adolesc. 2014;44(4):847-59.

\section{Submit your next manuscript to BioMed Central and take full advantage of:}

- Convenient online submission

- Thorough peer review

- No space constraints or color figure charges

- Immediate publication on acceptance

- Inclusion in PubMed, CAS, Scopus and Google Scholar

- Research which is freely available for redistribution 